\title{
As confissões da carne: o último volume da História da sexualidade de Michel Foucault ${ }^{12}$
}

\section{Confessions of the flesh: the last Michel Foucault's book of the History of sexuality}

Alexandre Filordi de Carvalho (i)

(i) Universidade Federal de São Paulo - Unifesp, Guarulhos, SP, Brasil. http://orcid.org/0000-00034510-9440, afilordi@gmail.com

[Foucault, Michel. (2018). Histoire de la sexualité: Vol. 4. Les aveux de la chair. Paris: Gallimard.]

Não é, portanto, totalmente a lei e seu conteúdo que mudaram, mas a experiência como condição de conbecimento. (Foucault, 2018, p. 364, tradução nossa)

\section{História da sexualidade IV: contexto geral e questão central}

As confissões da carne é o título do quarto e último volume da História da sexualidade de Michel Foucault. Publicado em fevereiro de 2018 na França, este texto inédito amplia estudos e investigações consagrados do autor sobre o desenvolvimento histórico das artes do cuidado e do governo de si mesmo, sob a extensa, variável e milenária cultura de práticas e de exercícios ascéticos.

\footnotetext{
1 Apoio: Fundação de Amparo à Pesquisa do Estado de São Paulo (Fapesp).

${ }^{2}$ Normalização, preparação e revisão textual: Andressa Picosque (Tikinet) - revisao@tikinet.com.br 


\section{pro.posıções \\ $e$-ISSN 1980-6248}

http://dx.doi.org/10.1590/1980-6248-2018-0131

Se com a publicação, em 1976, do primeiro volume da série, $A$ vontade de saber, Foucault dava início a um projeto incansável da história da sexualidade moderna, é sabido seu abandono visando perscrutar, numa espécie de alongamento genealógico, as bases mais "antigas" da sexualidade ocidental. Tal projeto, contudo, foi se delongando até que apenas em maio de 1984, no mês anterior à morte de Foucault, vem à luz $O$ uso dos prazeres, e em junho daquele mesmo ano $O$ cuidado de si, respectivamente volumes 2 e 3 da História da sexualidade.

Tanto $O$ uso dos praz̧eres quanto $O$ cuidado de si lançavam as investigações de Foucault para o extenso contexto greco-romano do espectro da cultura do cuidado de si e dos outros. As obras ressoavam, em boa dose, as lições de Foucault ministradas no Collège de France, especialmente a partir do curso Subjetividade e Verdade, proferido entre 1980 e 1981.

O aparecimento de As confissões da carne vem preencher uma lacuna analítica interposta entre $A$ vontade de saber e os demais volumes dessa coleção. No avertissement elaborado por Fréderic Gros para este quarto volume da História da sexualidade, compreendemos que foi Paul Veyne que estimulou Foucault a buscar cada vez mais fundo na histórica a problematização dos aphrodisia. Assim, esclarecem-se as razões internas da ulterioridade de As confissões da carne. Além disso, com a morte precoce de Foucault em junho de 1984, o pensador francês não teve tempo suficiente de rever o manuscrito inicial para sua imediata publicação. Como o seu testamento, elaborado em 1982, coibia a publicação de póstumos, o volume quarto da História da sexualidade não foi publicado.

Com a publicação de As confissões da carne, o seu leitor é introduzido em um universo textual distinto das obras anteriormente publicadas por Foucault, ao menos por duas razões. De um lado, encontramos um conjunto de temáticas um tanto quanto já conhecidas de seus leitores, como o uso dos prazeres, verdade e veridicção, dizer e fazer-verdadeiro, técnicas de governo da pastoral cristã, a arte da confissão e exame de si mesmo, domínio de si mesmo como governo de si e metanoia. Trata-se de um espectro nocional apresentado por Foucault nos cursos do Collège de France ministrados durante os anos 1980. De outro lado, o leitor se deparará com um terreno mais árido e desconhecido, pois Foucault percorreu minuciosamente o longo processo de consolidação doutrinária da igreja cristã em seus primeiros séculos. Não é fácil acompanhar a vultosa soma de temas doutrinários ao longo do volume 4 da História da sexualidade, ainda mais porque eles são tratados com uma formalidade rigorosa. Clemente de Alexandria, Gregório de 


\section{pro.posições \\ $e$-ISSN 1980-6248}

http://dx.doi.org/10.1590/1980-6248-2018-0131

Nazianzo, João Cassiano, João Crisóstomo, Tertuliano, Santo Agostinho, entre outros, não se encontram ao nosso lado com muita frequência.

Assim, entre o assombro do desconhecido, por vezes impenetrável ao primeiro olhar, e certos signos a reverberar sendas mais ou menos conhecidas, temos em mãos uma obra que não deixa de desafiar qualquer domínio acerca do estado da arte do pensamento de Michel Foucault.

Perfazendo na versão francesa quase quatrocentas páginas, o livro é subdivido em três partes: "A formação de uma experiência nova"; "Ser virgem"; "Ser casado" (tradução nossa). A versão francesa ainda traz quatro anexos que possuem estatutos distintos e retratam as diretrizes gerais da concepção da obra como se fossem esboços temáticos a serem desenvolvidos. No final desta resenha apresentamos a tradução integral do anexo 1.

A questão central de $A$ s confissões da carne, ou sua tese-guia, é anunciada desde as suas primeiras linhas e pode assim ser formulada: a complexa arte de conduzir a conduta dos indivíduos, fixada no Ocidente pelo cristianismo, bem como seu comportamento, avaliando os seus progressos e objetivos cuidadosamente, fazendo incliná-los à obediência restrita sob a direção de um guia da verdade e das verdades instauradas como guia, teve suas condições de desdobramento graças à filosofia pagã. Conforme propôs Foucault (2018, p. 10, tradução nossa), é preciso reconhecer que ao redor do regime dos aphrodisia, "definido em função do casamento, da procriação, da desqualificação do prazer”, logo, qualificando-o em outros termos, "e de uma ligação de simpatia respeitosa e intensa entre os casados ... [,] foi uma sociedade pagã que forneceu a possibilidade de reconhecer uma regra de conduta aceitável para todos".

Sob tal perspectiva, Foucault buscou mostrar as maneiras distintas pelas quais o cristianismo foi aclimatando os princípios-chave dos mestres de conduzir a conduta da Antiguidade e dos guias da vida ascética. Em jogo está a retomada da conhecida hipótese analítica apresentada por Foucault em $O$ uso dos prazeres: a Antiguidade foi perpassada por uma problematização rigorosa acerca da moral dos prazeres, por sua vez coextensiva a uma complexa rede de códigos, preceitos e observâncias indissociáveis de uma pragmática de si mesmo, intermediada pela presença do outro. Não foi no registo de um bel praz̧er, portanto, que o uso dos prazeres se constituiu, mas no registo de modos de subjetivação, demandando exercícios cuidadosos sobre a sua própria substância ética. A questão axial dizia respeito ao que fazer de si mesmo, com o intuito de alcançar, por elaboração ascética, isto é, por uma série de provas acerca 


\section{pro.posições \\ $e$-ISSN 1980-6248}

http://dx.doi.org/10.1590/1980-6248-2018-0131

do domínio sobre si mesmo, uma atitude finalizadora sobre si mesmo, ou seja, um modo de ser preciso.

Desse ponto de vista, o cristianismo reverberou toda a tradição ascética quando se tratou de concebê-lo desde a perspectiva da filigrana histórica das forças constituintes e presentes no jogo do uso subjetivo da "carne" cristã. Ao dizer "uso subjetivo", é preciso considerar o fundo de formação de subjetividade aí envolvido:

exercício de si sobre si mesmo, conhecimento de si por si mesmo, constituição de si mesmo como objetivo de investigação e de discurso, liberação, purificação de si mesmo e salvação por intermédio de operações que trazem a luz até o fundo de si, conduzindo os segredos mais profundos até a luz da manifestação redentora. (Foucault, 2018, p. 50, tradução nossa)

Por conseguinte, é toda uma série analítica de como a formação da subjetividade cristã, que fazia da "carne" a sua substância ética a ser manejada visando a constituição de um sujeito teleologizado, passou a se anunciar como a cena incontornável de um tipo de relação de poder cujo jogo de verdade não abria mão de uma ascética instituída. Seja como for, em termos de Foucault (2018, p. 106, tradução nossa),

a direção espiritual, o exame de si mesmo, o controle atento por parte do sujeito de seus atos e de seus pensamentos, a exposição que ele se permite ao outro, a demanda de conselhos a um guia e a aceitação de regras de condutas a que se propõe: todo isso é uma tradição muito antiga.

Sendo assim, ao longo das mutações situadas na composição histórica dos nós prescritivos do cristianismo, que é dependente deles, podemos também vislumbrar as consequências mutantes de uma série de experiências imprescindíveis para as novas definições de vínculos entre subjetividades e verdades. Nesse caso, é precisamente a "carne" o ponto de saída e de chegada de toda problematização cristã ao redor de como uma determinada experiência de subjetivação poderia se tornar, ao mesmo tempo, um reflexo de um duplo espelho dos atos do fazer-verdadeiro e do dizer-verdadeiro. A "carne", então, "compreende um modo de experiência, isto é, um modo de conhecimento e de transformação de si por si mesmo, em função de determinada relação entre anulação do mal e manifestação da verdade" (Foucault, 2018, p. 50-51, tradução nossa). Interessou a Foucault precisamente fazer a história da formação da "carne" cristã, ou seja, da substância ética com a qual e a partir da qual foi se constituindo o próprio modo de subjetivação cristão, um modo de ser preciso e calibrado em uma extensa plataforma ascética cujas referências compuseram o próprio modo de ser cristão. 


\section{pro.posıções \\ $e$-ISSN 1980-6248}

http://dx.doi.org/10.1590/1980-6248-2018-0131

Em algum ponto e sob alguma medida, o Ocidente cristianizado se viu e se vê face a face com a extensão consequente da constituição dessa "carne". Ainda que silenciosamente, corremos o risco de confessá-la diante do gesto banal do peso da consciência ou da confissão deliberada dos desejos mais recônditos, como Foucault (1999, p. 59) já havia apontado na célebre passagem de $A$ vontade de saber:

A confissão difundiu amplamente seus efeitos: na justiça, na medicina, na pedagogia, nas relações familiares, nas relações amorosas, na esfera mais cotidiana e nos ritos mais solenes; confessam-se os crimes, os pecados, os pensamentos, os desejos, confessam-se passado e sonhos, confessa-se a infância; confessam-se as próprias doenças e misérias; emprega-se a maior exatidão para dizer o mais difícil de ser dito; confessa-se em público, em particular, aos pais, aos educadores, ao médico, àqueles a quem se ama; fazem-se a si próprios, no prazer ou na dor, confissões impossíveis de confiar a outrem, com o que se produzem livros. Confessa-se - ou se é forçado a confessar.

Ora, no caso de As confissões da carne, e, certamente, de nossa "carne", herdeiros colonizados que somos do cristianismo, a "carne" confessada processou-se quando a ideia de concupiscência como mal se instalou nas condutas sexuais. Desde então, a experiência sexual passou a conhecer, sobretudo tendo o matrimônio heteronormativo como centro de controle de concessões possíveis e impossíveis para se efetivar a economia do prazer, o lugar da própria analítica do sujeito da concupiscência, cuja conduta sexual deveria ser profissão de fé ao dizer e ao fazer-verdadeiro, balizada pelas regras implacáveis de examinar-se a si mesmo. Nos termos de Foucault (2018, p. 361, tradução nossa),

o ato sexual no mundo antigo é pensado como "bloco paroxístico", unidade arrebatadora (unité convulsionnelle) em que o indivíduo se esgotava em prazer com o outro, ao ponto de flertar com a morte... No cristianismo, esse bloco foi desfeito por regras de vida, de artes de se conduzir e de conduzir os outros, de técnicas de exames ou de procedimentos de confissão, por uma doutrina geral do desejo, da queda, da falta, etc.

Por conseguinte, a "carne" cristã emergiu como marcador condicionante de uma formação subjetiva que passou a fazer oposição a toda economia do "prazer paroxístico" da Antiguidade, cedendo lugar à "analítica do sujeito da concupiscência". Por extensão, Foucault nos faz entrever, numa espécie de hipótese de fundo constitutivo de nós mesmos, que os modos pelos quais se mantêm as destinações voltadas ao prazer, este, por sua vez, constituído em boa medida com a herança histórica das experiências sexuais governadas pela forte presença da “carne” cristã, são uma dívida impagável de nossos nós culturais. Tais nós culturais - expressão utilizada por Foucault no livro -, no lugar de desfazer a força das amarras da "carne" cristã, 


\section{pro.posições \\ $e$-ISSN 1980-6248}

http://dx.doi.org/10.1590/1980-6248-2018-0131

claro está, tiveram desde Santo Agostinho, com a ideia de homem interior, uma inclinação para reeditar, em termos nietzschianos, a má consciência acerca do prazer. Nesse contexto, como destacou Foucault (2018, p. 234, tradução nossa), se João Cassiano usava mencionar a necessidade de se "sair da carne permanecendo, todavia, no corpo", outrossim, com As confissões da carne, passamos a saber por que não mais saímos da "carne" que insiste fazer morada em nosso corpo. E, assim, seguimos confessando-a, ainda que sem palavras.

\section{Desenvolvimento geral de As confissões da carne}

Para percorrer a complexa composição da experiência da "carne", o quarto volume da História da sexualidade apresenta três movimentos históricos que, embora distintos entre si, acabam produzindo uma espécie de andaime interligado cujos níveis se intercomunicam entre partes inferiores e superiores. Duas vertentes gerais estão aí implicadas. De um lado, houve etapas históricas decisivas para a composição da experiência da "carne" até a sua fixação como presença inevitável de nossa herança com certas verdades dirigidas para o uso do prazer. De outro lado, em cada etapa houve um refinamento de técnicas e estratégias tendentes a articular o acesso da verdade para se formular relações de si para si mesmo com vistas à subjetivação, mas sempre sob a intervenção de um guia figurado no mestre da conduta ou no diretor espiritual, marca indelével da pastoral cristã.

No primeiro movimento, denominado "A formação de uma experiência nova", Foucault explorou como, ao redor de certas práticas penitenciais, sobretudo as atinentes ao batismo e aos exames como procedimentos de provas do convertido, a "carne" era constituída como experiência designada por um regime disciplinar austero e positivo, "uma maneira de ser e de viver, um regime que envolve habitus atque victus" (Foucault, 2018, p. 94, tradução nossa), não como ligação dos seus sujeitos a um conjunto de atos praticados cegamente, mas muito mais como associação a um estatuto subjetivo. "A penitência assim praticada não é simplesmente um ato, ou uma série de ações, mas um estatuto" (Foucault, 2018, p. 83-84, tradução nossa).

Com efeito, a história da prática penitencial que Foucault elaborou visou mostrar justamente essa nova experiência de acesso aos jogos de verdades responsáveis por calibrar a formação subjetiva dos sujeitos neles envolvidos. Seja como for, a prática penitencial ativava a 


\section{pro.posições \\ $e$-ISSN 1980-6248}

http://dx.doi.org/10.1590/1980-6248-2018-0131

exomologése e a exagoreusis, de modo decisivo, como exercícios necessários para o sujeito testificar seu verdadeiro lugar na forma correta de se subjetivar, ou seja, fornecendo provas visíveis de sua maneira de se constituir como sujeito, com a sua própria "carne".

A exomologése, então, era a manifestação da verdade por meio de ritos penitenciais, de exames privados e públicos que objetivavam dar provas de que se estava obtendo a conduta desejada. Para isso, todavia, era imprescindível uma constante atenção sobre si mesmo. A exagoreusis concernia à constante necessidade de o sujeito manifestar pela linguagem, quer dizer, de uma discursividade obrigatória, o rosto da verdade inconfundível entre atos e o dizerverdadeiro. Dessa maneira, para além das atitudes, o sujeito cristão tinha que confessar suas verdades como prova de um ato de conhecimento do mais profundo de si mesmo. Eis aí, segundo Foucault (2018, p. 369, tradução nossa), a nossa "propensão ao discurso e à vontade de saber que caracterizam a experiência de si e dos outros em nossas sociedades".

Ora, todo esforço dos atos penitenciais circunscritos ao fazer-verdadeiro (exomologése) e do dizer-verdadeiro (exagoreusis) passava pelo estudo constante do corpus doutrinário organizado pela igreja. Para o ingressante no cristianismo, era obrigatório o estudo da Didakhê, isto é, de toda doutrina cristã já sistematizada, responsável por servir de arrimo para o catecumenato.

O catecumenato constitui um tempo de preparação extenso (pode durar três anos) no qual a catequese e o ensino das verdades e das regras estão associados com um conjunto de prescrições morais, de obrigações rituais e práticas, além de deveres. (Foucault, 2018, p. 66, tradução nossa)

Passado uma vez pelo catecumenato, seguindo as provas penitenciais do batismo e dos ritos da conversão, tal como a confissão constante e a observação das condutas, o sujeito convertido ao cristianismo jamais deixaria de dar provas consistentes da eficácia de sua instrução a fim de saber governar-se a si mesmo, donde o mote central haveria de acompanhá-lo até a vida eterna - instituere et gubernare, instruir e governar -, pois governar-se a si mesmo é uma prova constante de si mesmo sob o jogo atentivo e vigilante do domínio das forças que, sobretudo, estão presentes no desejo, ou minimamente desde Agostinho, como ressalta Foucault (2018), na libido: a forma involuntária do desejo que precisa ser governada.

Esse contexto todo, e isso é importante sublinhar, ligava o sujeito cristão a uma tradição que o orientava em sua constituição. Em outros termos, o preparo do cristão ativava provas de respeito a um passado imprescindível para a sua formação como sujeito em um presente. $\mathrm{O}$ tempo de preparação para se tornar cristão, embora a conversão como metanoia fosse um 


\section{pro.posições \\ $e$-ISSN 1980-6248}

http://dx.doi.org/10.1590/1980-6248-2018-0131

marcador importante, não abdicava das provas necessárias em um constante presente, ativando um modo de conduta impossível de existir fora de um passado cujo contorno concedia condições históricas para que seus sujeitos se localizassem em seus propósitos existenciais.

Entretanto, o presente irrompe como uma atualização de prova de si mesmo que, embora busque a justificação do passado, opera a força concreta de um que fazer na atualidade. Para tanto, a alteridade assumia lugar central na economia dessa constituição subjetiva, quer seja pelo fato de haver a figura central do pastor para cuidar da formação doutrinária do cristão, quer seja pelo fato de haver uma consistência subjetiva em formação, poderíamos dizer fora do estatuto atual do sujeito, que precisava ser alcançada como alteridade ideal a ser atingida.

Dessa maneira, o segundo movimento de As confissões da carne, denominado "Ser virgem", dá a conhecer a dimensão da prática de si ao redor da contingência da carne e do conhecimento de si mesmo a ser atingidos, tendo a virgindade como o ápice da força positiva capaz de ensejar provas de um combate ascético que sustenta um número de propósito nobre: dominar-se a si mesmo.

Foucault (2018, p. 200, tradução nossa) argumentava que a mística da virgindade, tanto masculina quanto feminina,

mostra que a excessiva valorização de uma abstenção total, originária e definitiva de relações sexuais não tinha uma estrutura de proibição, ela não representava o simples prolongamento de uma economia restritiva dos prazeres do corpo. A virgindade cristã, ao contrário, é a forma radical ou exasperada de um preceito de contingencia moral que a moral filosófica conhecia muito bem na Antiguidade e cujos primeiros séculos cristãos haviam herdado.

Com a temática da virgindade temos, então, outro efeito prático do passado sobre o presente. A virgindade introduz uma série de técnicas de domínio sobre si mesmo com o propósito de valorizar a relação do sujeito com a sua própria conduta sexual. Aliás, para Foucault (2018, p. 202, tradução nossa), "o lugar central do sexo na subjetividade ocidental já se marca claramente na formação dessa mística da virgindade". Tal hipótese não deixa de anabolizar a destituição mítica do século XIX como experiência fundadora da centralidade do sexo na subjetividade ocidental, como a intelligentsia freudiana ousa reivindicar e que Foucault já combatera em $A$ vontade de saber.

Nesse horizonte, é importante considerar que o que está em jogo é a atualização constante de uma ascética. Em outros termos, a virgindade é um campo de ativação de um 


\section{pro.posições \\ $e$-ISSN 1980-6248}

http://dx.doi.org/10.1590/1980-6248-2018-0131

presente que se atualiza como prova e combate constantes para os quais é imprescindível mostrar que se está preparado. Em tal cenário, ademais, invoca-se o elemento irredutível da alteridade, porque mais do que a exigência de um trabalho sobre si mesmo, ou seja, uma demanda atenta de controle e medida de suas próprias forças, a luta ascética ao redor da virgindade exige um constante posicionar-se diante do outro, nem que seja satanás, como prefiguração do tentador pronto a sabotar o empenho das forças que visam aplicar o sujeito em sua constituição.

Ora, o presente da "carne" que se atualiza depende do constante domínio de exercícios e práticas, das tomadas de consciência e de ações indispensáveis para uma ética do cuidado de si mesmo. Por conseguinte, trata-se de considerar que o presente se materializa como condição de partida para manter a finalidade atualizada da ascética. Curioso notar, contudo, como os termos "surveiller" (vigiar) e "vigilance" (vigilância) ganham contornos de positividade absolutamente distintos das tão conhecidas estratégias de vigiar e vigilância empregadas nas formas de poder da sociedade disciplinar. Na ascética cristã, vigar-se a si mesmo, além de toda vigilância, denota a ação ativa do sujeito sobre si mesmo, empenhado em realizar sua subjetivação. Não é sem sentido a farta argumentação de Foucault (2018, p. 244-245, tradução nossa):

O que está em jogo, então, não é um código de atos permitidos ou proibidos, é toda uma técnica para vigiar (surveiller), analisar e diagnosticar o pensamento, suas origens, suas qualidades, seus perigos, suas potencialidades de sedução e todas as forças obscuras que podem se esconder sob o aspecto em que ela se apresenta. E se o objetivo é finalmente expulsar tudo o que é impuro ou induz à impureza, só se pode estar atento senão por uma vigilância (vigilance) constante, uma suspeita que se deve carregar para todos os lugares e em cada instante contra si mesmo... Nessa ascese da castidade, pode-se reconhecer um processo de "subjetivação" que relega para longe uma ética sexual centrada sobre a economia dos atos. Mas é preciso também sublinhar duas coisas. Essa subjetivação é indissociável de um processo de conhecimento que faz da obrigação de procurar e de dizer a verdade de si mesmo uma condição indispensável e permanente dessa ética. Se a subjetivação existe, ela implica uma objetivação indefinida de si para si - indefinida no sentido de que, não estando adquirida de uma vez por todas, ela não cessa no tempo. Além disso, essa subjetivação em forma de busca da verdade de si se efetua através de complexas relações com os outros. E de várias formas: porque se trata de descobrir em si a força (puissance) do Outro, do Inimigo que se esconde sob as aparências de si mesmo; porque se trata de levar contra este Outro um combate incessante do qual não se sai vitorioso sem o socorro do TodoPoderoso, que é mais forte que o Inimigo; porque, enfim, a confissão aos outros, a submissão a seus conselhos, a obediência permanente aos diretores são imprescindíveis ao combate. 


\section{pro.posições \\ $e$-ISSN 1980-6248}

http://dx.doi.org/10.1590/1980-6248-2018-0131

O terceiro e último movimento de $A$ s confissões da carne aborda a dimensão mais presente e atual do conjunto de técnicas e estratégias que se desenvolveram como experiência universal e generalização indefinida da arte de governar cristã: "Ser casado". O matrimônio é concebido em um complexo contexto de problematização das condutas sexuais sob a égide da dupla relação dever e dívida. Cada sujeito, no matrimônio, situa-se no influxo da "pastoral da vida cotidiana" (Foucault, 2018, p. 252, tradução nossa) cuja exigência de respostas ao dever mútuo implicado na gestação e na gestão das relações entre homem e mulher situava o casamento em uma dívida sub judice eterna. O jogo duplo de obediência, servilismo, dizer-verdadeiro e fazerverdadeiro, respeito à hierarquia - no caso a irrefutável submissão da mulher ao homem -, o princípio de ensino e de aprendizagem escalonada - o homem que guia a mulher e a mulher guiada pelo homem -, tudo isso se presentificava na junção dupla: dever e dívida matrimonial, assim como a Igreja se inseria na relação dever e dívida com Cristo. Não sem sentido, o retorno à constante ligação da submissão da Igreja a Cristo que deveria ser o modelo instituído para todo casamento é o argumento inapelável: "É a mesma obediência que deve ligar a mulher ao homem; a mesma preeminência dele sobre ela; a mesma tarefa de educação, a mesma acepção do sacrifício para se salvar” (Foucault, 2018, p. 259, tradução nossa).

Não seria de todo equivocado dizer que encontramos em "Ser casado" interessantes pistas acerca de uma genealogia do machismo instalado e cristalizado no Ocidente. Nesse caso, com certeza há uma potência analítica que pode ser explorada em pesquisas futuras, pois Foucault destrincha cum grano salis essa interessante proveniência, e por que não dizer Herkunft, de um machismo que se institucionalizou nas relações maritais, fazendo-nos compreender, ao mesmo tempo, as razões pelas quais ele se institucionalizou.

Se São João Crisóstomo, como citou Foucault (2018, p. 259, tradução nossa), afirmava que "o lar (le ménage) é uma pequena Igreja”, por certo todo um núcleo de fundamentação doutrinária, com o seu velho e incansável jogo de verdade, também haveria de fundamentar as relações entre homem e mulher, sobretudo porque o casamento, para o cristianismo, era "uma maneira, ao lado ou mais abaixo da virgindade, de regular a questão da concupiscência" (Foucault, 2018, p. 273, tradução nossa). Ou seja, em sua essência o casamento foi uma estratégia de limitar o desejo, uma política instituída e reconhecida instalada na lógica do controle da "carne" e do que a "carne" era autorizada e como era autorizada a se instalar na economia do desejo. Em termos mais simples, quem não pode dominar a si mesmo ao ponto de se manter 


\section{pro.posições \\ $e$-ISSN 1980-6248}

http://dx.doi.org/10.1590/1980-6248-2018-0131

virgem, então, que se case. Portanto, consequência geral da ascética cristã, ao menos desde o século IV, “o matrimônio é por si mesmo uma lei” (Foucault, 2018, p. 273, tradução nossa).

Por ser uma lei, o matrimônio se desdobrou como forma social de fazer circular uma série de obrigações responsáveis por embasar os condicionantes sociais das futuras sociedades cristãs. Conforme sustentou Foucault, a teologia de Santo Agostinho foi o marco decisivo para institucionalizar um vasto conjunto de fundamentos que passaram a exigir das relações conjugais uma tekhnê da vida.

É importante destacar três aspectos nesse sentido. Em primeiro lugar, a presença das relações sexuais no matrimônio passou a estar ligada a uma concepção geral do homem de desejo. Depois da expulsão de Adão e Eva do Paraíso, por desobediência e transgressão de uma regra de conduta, a concupiscência da "carne" passou a ser "um castigo que exerce seu império sobre o homem" (Foucault, 2018, p. 344, tradução nossa). Por sua vez, toda "carne" passou a atentar contra o espírito. Assim, a libido, termo que Santo Agostinho utilizava associando o desejo à falta e à queda, tornou-se um princípio de reciprocidade de desobediência, espécie de "movimento que atravessa e conduz todos os atos sexuais, fazendo-os às vezes visíveis e vergonhosos, e ligando-os à morte espiritual como sua causa" (Foucault, 2018, p. 338, tradução nossa). Sendo assim, é imprescindível governar as condutas nas relações sexuais, e para bem governar a libido, a alternativa contra a abstenção imposta aos anacoretas, aos homens e às mulheres "casados" com Cristo, bem como à aceitação voluntária da virgindade, passou a ser o matrimônio assumido como sacramento: o lugar sagrado em que a libido se transformou em pauta de governamento.

Com efeito, em segundo lugar, estabeleceu-se uma política da direção do uso do matrimônio, ou seja, do uso da "carne" no matrimônio. Estar casado, assim, implica no estrangulamento da relação dever e dívida. Tanto homem como mulher passam a dever, um ao outro, a dívida impagável de concessões inegociáveis: a proibição de relações naturais, donde podemos inferir o fundamento persecutório e proibitivo das relações homoafetivas; o respeito ao homem como chefe do lar ou governador das relações maritais, por intermédio do princípio da legalidade; a mulher concebida como mera auxiliar do homem, regra fundamentada no princípio da complementariedade; o homem instituído como o guia da mulher, eixo norteador do princípio do ensinamento ligado ao respeito ao pudor e ao diluimento da autonomia vigiada pela pastoral cristã. Eis aí alguns exemplos de uma série histórica analisada por Foucault em $A s$ 


\section{pro-posıções \\ $e$-ISSN 1980-6248}

http://dx.doi.org/10.1590/1980-6248-2018-0131

confissões da carne que nos permite compreender o matrimônio cristão inaugurando um tipo jurídico de práticas em que a estrutura de seu sujeito é dupla: sujeito do desejo regido pela concupiscência que precisa ser governada; sujeito do direito a partir da juridicção (juridiction) da carne. Implica dizer que o matrimônio, desde o cristianismo, é uma experiência incessante de codificação e de larga reflexão de jurisprudência, conforme Foucault evidenciou a partir da página 282.

Finalmente, levando ao limite a direção da libido e do direito sobre o matrimônio, Foucault destacou o casamento como connexio societatis, ou seja, como "fim universal e constante da societas" (Foucault, 2018, p. 310, tradução nossa). A sociedade ocidental cristianizada reconheceu no casamento a base primeira das condições de sua formação e do lastro de sua estabilidade, fazendo da conexão ou dos laços instituídos pela pastoral da vida cotidiana lugar privilegiado e laboratorial de como homens e mulheres deveriam se colocar em associação. Assim, "o privilégio acordado na societas permite dar uma caracterização do casamento centrado na noção de vínculo (lien). O matrimônio é, antes de todas as coisas, uma associação e, como tal, um elemento da base da sociedade" (Foucault, 2018, p. 310, tradução nossa).

Regido pela fidelidade e pelo peso sacramental, desde o cristianismo o matrimônio foi colmatando com as suas estratégias juridiccionais de conexões sociais qualquer tipo de relacionamento contrário às suas próprias lógicas de relações de poder pastoralizantes. O uso dos prazeres, desde então, encontra-se cifrado pelas convenções de apoio duplo: de um lado, o matrimônio heteronormativo como microssociedade reverberando as estratégias de condução da pastoral cristã; de outro, a pastoral cristã se hiperatrofiando na medida em que fazia incidir sobre o casamento heteronormativo o macrocosmo redentor de sua juridicção, sempre à guisa de uma "concepção geral do homem do desejo e de uma fina juridicção dos atos sexuais, marcando profundamente a moral do Ocidente cristão" (Foucault, 2018, p. 324, tradução nossa).

As palavras finais de As confissões da carne, a partir de todo o contexto assinalado pela análise da emergência da "carne" cristã como "A formação de uma experiência nova", passando pela temática de "Ser virgem" e, finalmente, "Ser casado", bem assinalam a dupla tensão desse grande e forte nó cultural que foi e continua sendo o cristianismo na civilização ocidental. A partir de então, deixamos de experimentar o prazer e os lugares do "antigo" corpo associado ao "bloco paroxístico" do prazer do mundo greco-romano para sermos batizados com o sinal 


\section{pro.posıções \\ $e$-ISSN 1980-6248}

http://dx.doi.org/10.1590/1980-6248-2018-0131

incontornável da "analítica do sujeito da concupiscência". Com o cristianismo, o corpo foi sepultado e o que ressurge no seu lugar é a "carne", mapeada por intensidade de poder que a disciplinou para a contenção, para a finalidade conjugal, para o sexo instrumentalizado e para o desejo associados à impureza e à falta. Eis aí uma tradição que está longe de se desvanecer como, na orla do mar, um rosto de areia. Mais do que isso, "aí estão vinculados, por vínculos pelos quais a nossa cultura mais se inclinou do que desfez, o sexo, a verdade e o direito" (Foucault, 2018, p. 361, tradução nossa).

\section{Referências}

Foucault, M. (1999). História da sexualidade: Vol. 1. A vontade de saber (13a ed.). Rio de Janeiro:Graal.

Foucault, M. (2018). Histoire de la sexualité: Vol. 4. Les aveux de la chair. Paris: Gallimard.

Submetido à avaliação em 16 de novembro de 2018; aceito para publicação em 11 de dez̧embro de 2018.

\section{Anexo 1}

O que se trata de mostrar:

1. Existe um nó prescritivo relativamente constante no cristianismo. Esse nó é antigo. Ele se formou antes dessa religião e é atestado claramente por autores pagãos da época helenística e romana.

2. Esse nó pode ser encontrado sem maiores modificações nos Apologetas do século II. Clemente de Alexandria integra esse nó com sua teologia de inspiração platônica, bem como um conjunto de preceitos morais de inspiração estoica.

3. É a nova definição de relações entre subjetividade e verdade que vai dar a esse antigo nó prescritivo uma significação inédita e fornecer importantes modificações à antiga concepção de prazeres e de suas economias. 


\section{pro.posições $e$-ISSN 1980-6248}

http://dx.doi.org/10.1590/1980-6248-2018-0131

4. Essas modificações incidem menos sobre a divisão entre permitido e proibido e mais sobre a análise do domínio das aphrodisia e do modo de relação que o sujeito é incitado a ter com ele. Não é, portanto, totalmente a lei e seu conteúdo que mudaram, mas a experiência como condição de conhecimento. 